\title{
Nursing care and teleorientation in Brazil
}

\begin{abstract}
This article aims to present, in a brief way, how communication and information technologies have helped health care in Brazil, both in the public and private sectors, being with the formation, training and permanent education of professionals, the diagnosis assistance in regions of difficult access or with scarce resources and through teleorientation, where the population's doubts about health are remedied, providing personal empowerment, greater access to information, improved decision-making and a favorable behavior change, becoming an important asset for the health promotion.
\end{abstract}

Keywords: nursing care, teleorientation, treatment, care, life quality
Volume 5 Issue 2 - 2018

\author{
Maria Elisa Gonzalez Manso,' Leandro Tadeu \\ Prazeres Maresti, ${ }^{2}$ Andréia Veloso Aosti ${ }^{2}$ \\ 'Social Gerontology Program - PUC SP, Brazil \\ ${ }^{2}$ Nursing graduation program, UNIP - SP, Brazil
}

Correspondence: Maria Elisa G. Manso, Social Gerontology Program - PUC SP, Brazil, Tel +55-I I 99365263।, Emailmansomeg@hotmail.com

Received: April 09, 2018| Published: April 23, 2018

\section{Introduction}

Access to health services in Brazil is a multifaceted and multidimensional theme. Today the country contains two parallel health systems: a public and a private one. The first, named Unified Health System (SUS), serves the population universally, with primary care as its main gateway. The second, which is the private sector, is characterized by the commercialization of health plans, possessing income-related access and providing coverage to approximately $30 \%$ of the total Brazilian population. Both, however, are characterized by the still incipient use of technologies that could help in attention to health. ${ }^{1}$ The use of Information and Communication Technologies (ICT) in the health sector has modified the clinical practice and its routines as well as the forms of relationship between patients and professionals of the area.

In Brazil, it has been mostly used to (i) process data, images and voices, (ii) storing and retrieving of data, images and voices, and (iii) communication. $^{2}$

\section{Discussion}

Among the various ICTs, telehealth (telemedicine, e-health) is one that must be highlighted, it is a technology that seeks to offer health care and services from afar. In the SUS system, telehealth is already a fact since 2007, with actions that aim to speed up and improve the quality of care. It is used as a training and support element for primary care teams (Family Health Strategy) throughout the country. ${ }^{3}$ As Brazil is characterized by a wide territory filled with places of difficult access, tele-health, through the performance of consulting, diagnosis and second opinions, assists in the attendance of specialized situations to which, otherwise, the people who live in such localities would not have access to. ${ }^{3}$ While the SUS prioritizes telehealth as a toll for the better education of their workers and improving patient care, in the private sector, it is also used to relay reliable health information to their users. The Brazilian population has frequent questions related to health /illness and often seeks said information from unreliable sources and/or end up overburdening health services unnecessarily, hence the importance of this type of service, which is much more focused on health promotion than on care. In São Paulo, a company in the private health sector has implemented, since 2012, a health information program that uses technological resources involving a large database, built according to the best scientific evidence, brief text messages and social networks in order to provide information and guidance to users of health plans.

In addition to these tools, the company also provides information through teleorientation, through a telephone call center composed solely of nurses that is available 24 hours a day, a service that is capable of applying Screening protocols, solving various health/illness related doubts, encouraging a healthy lifestyle and, with these said actions, turn possible that, even from afar, simple questions can be resolved in quickly fashion. The constant search for this teleorientation service, which receives around five thousand calls per month, demonstrates the need of the population to have access to more reliable information related to health issues, as well as a greater confidence of the users in the service provided by the involved team.

The public of these services is constituted mostly of young women and the elderly. Of the most requested information, the majority refers to chronic diseases and the use of the most diverse medications. As an example, in relation to diabetes, the main questions were about the causes of the disease; which factors worsen the clinical picture; questions about which diet is the most appropriate; what physical exercises to perform; the relation of the disease to the stress of daily life; side effects of medications; when it is necessary to start the treatment; if there is a definite cure; and many concerns about the interactions between the various medications. Other inquiries are related to the complications of the disease; what are the main consequences of diabetes; which signs and symptoms are characteristic of complications; what is recommended as prevention and if there is a possibility of reversion of the picture.

Regarding the medications, the main doubts were about the use of oral contraceptives and injectable, mainly: how to use them; their interaction with drugs, food and drinks; the effectiveness of the method; contraindications for their use and adverse reactions and effects of these drugs. Failures were observed in the doctor-patient relationship, since most of the doubts pointed out would be easily clarified through an effective dialogue in which the professional is prepared to respond to all questions, is welcoming to the person and seeking to understand the cultural, social, psychological and economic aspects of the individual. 
When communication occurs, one person presents his or her idea to the other and both try to work it out in an agreement of thoughts and understanding, provided they are willing to listen freely, without prejudice and without fear of novelties. Acting authoritatively, imposing opinions or understanding the other as passive, are actions that do not match a profession that requires a relationship based on listening, welcoming and caring for its effective performance. ${ }^{4}$ Nowadays, it is criticized how health professionals generally think that they are listening carefully to what the patient says, but preformed assumptions and opinions about what people should and should not do lead them to label certain doubts or anxieties of their patients as ignorance. On the other hand, the patients may refrain themselves from asking about something that the professional might consider obvious, even if it is a recurring or major doubt. ${ }^{5}$

Several researches conducted in Brazil and in the US show that health professionals tend to use the so-called "technical jargons" in the vast majority of their encounters with patients, mostly without even realizing it. In a study conducted with American family medicine professionals, it was found that there is use of technical jargons in approximately $40 \%$ of the recommendations and $30 \%$ in health education actions, with quite low related patient understanding rates. ${ }^{6}$ With the implementation of the program of teleorientation, it was perceived how simple doubts or miscommunication about subjects related to health negatively impact the health of these people. Understanding that the nurses have an active participation in the education process, the program has been testing new technologies and approaches, such as internet support groups and patient communities, since numerous studies show the positive correlation between participation in these communities and the increase of emotional wellbeing.

\section{Conclusion}

Telehealth is used in Brazil, therefore, as a facilitator for the formation, training and permanent education of health professionals, as an auxiliary in the attention to the health of people in places of difficult access or scarcity of resources and as an instrument for narrowing the professional health-patient relationship. In this last aspect, the teleorientation carried out by specialized nurses, in their various forms, can provide personal empowerment, greater access to information, improved decision making and a favorable behavior change, becoming a very important tool in health promotion.

\section{Acknowledgements}

None.

\section{Conflict of interest}

Authors declare no conflicts of interest with this manuscript.

\section{References}

1. Santos IS, Ugá MAD, Porto SM. O mix público-privado no sistema de saúde brasileiro: financiamento, oferta e utilização de serviços de saúde. Ciênc Saud Col. 2008;13(5):1431-1440.

2. Schmeil MA. Saúde e Tecnologia da Informação e Comunicação. Fisioter mov. 2013;26(3).

3. Telessaúde Brasil Redes na Atenção Básica à Saúde. Brazil.

4. Bohm D. Diálogo: comunicação e redes de convivência. São Paulo: Palas Athena; 2005.

5. Manso MEG. Saúde e Doença: do controle sobre os corpos á perspectiva do adoecido. São Paulo: Max Limonad; 2015.

6. Castro CM, Wilson C, Wang F, et al. Babel babble: physician's use of unclarified medical jargon with patients. Ame J Health Behav. 2007;31 Supply 1:S85-S95. 